\title{
Location of the three major agglutinogens of Bordetella pertussis by immuno-electronmicroscopy
}

\author{
N. W. PRESTON, A. A. ZORGANI and E. J. CARTER
}

\begin{abstract}
Pertussis Reference Laboratory, Department of Medical Microbiology, University Medical School, Manchester M139PT
\end{abstract}

Summary. When the three serotypes of Bordetella pertussis (types 1,2,3;1,2 and 1,3) were labelled with agglutinins and protein-A gold, agglutinogen 1 was found on fimbriae and on the cell surface of types 1,2,3 and 1,2 but on the cell surface only of non-fimbriate type 1,3 organisms. In contrast, agglutinogen 2 was located on fimbriae only. Agglutinogen 3 was not labelled. When protein-A gold was replaced by immunoglobulin-G gold, agglutinogen 3 was found on the cell surface only, even of fimbriate bacteria of type 1,2,3. The implications of these findings for acellular vaccines are discussed.

\section{Introduction}

That there are three major agglutinogens (numbered 1,2 and 3 ) on the surface of different serotypes $(1,2,3 ; 1,2$ and 1,3$)$ of Bordetella pertussis is widely recognised, and their likely rôle in bacterial adhesion to the respiratory mucosa is also acknowledged. Agglutinogen 2 has been reported to be fimbrial by many workers, ${ }^{1-4}$ as has agglutinogen 3 by some, ${ }^{1}$ although fimbriae were not found on type 1,3 strains tested for serological purity immediately before electronmicroscopy. ${ }^{2}$ There is a dearth of evidence on the precise location of agglutinogen 1 .

In the present study, the relation of these agglutinogens to the structure of the bacterial surface has been examined by immuno-electronmicroscopy.

\section{Materials and methods}

\section{Serotyping of $B$. pertussis cultures}

Slide agglutination tests with rabbit antisera, ${ }^{5}$ monospecific for agglutinogens 1, 2 and 3, were done on each washed bacterial suspension immediately before it was prepared for electronmicroscopy. The serological purity of the previous subculture of the strain was tested by showing that 10 single-colony subcultures gave the same agglutination pattern with the three typing sera. ${ }^{6}$

\section{Strains of B. pertussis}

In a previous study of fimbriae, ${ }^{2}$ isolates sent to the Pertussis Reference Laboratory for serological typing

Received 13 Sep. 1989; accepted 22 Nov. 1989 were used. In the present study, a representative selection of these from many parts of Britain, of serotypes $1,2,3$ (strains K19587 and 18335), 1,2 (strains 85068 and 8002) and 1,3 (strains A36752 and 220822), was examined. They had been maintained lyophilised.

\section{Immunogold labelling and electronmicroscopy}

Up to six cultures were inoculated on sectors of a single petri plate of Charcoal Blood Agar (Oxoid), to provide identical cultural conditions for the comparison of different strains, and they were incubated for 2-3 days at $36^{\circ} \mathrm{C}$. The organisms were suspended in phosphatebuffered saline, $\mathrm{pH} \mathrm{7.4} \mathrm{(PBS),} \mathrm{and} \mathrm{washed} \mathrm{three} \mathrm{times} \mathrm{by}$ centrifugation and resuspension in PBS.

A formvar carbon-coated grid $^{2}$ was floated for $5 \mathrm{~min}$ on a drop of bacterial suspension, and drained by touching it with a piece of filter paper. It was then floated for $60 \mathrm{~min}$ on a drop of typing serum with an agglutinin titre of $c .1$ in $1000,{ }^{5}$ drained, and washed by floating it for $1 \mathrm{~min}$ on each of five successive drops of PBS containing Tween $200 \cdot 1 \%$ (PBS-T). As a control, to detect non-specific labelling, the typing serum was replaced with PBS-T.

The grid was then floated for $60 \mathrm{~min}$ on a drop of goldlabelling reagent, either Auro-probe EM protein-A reagent G10 (PA-Au) or Auro-probe EM goat antirabbit-IgG reagent GAR10 (IgG-Au); each reagent contained gold particles of 10-nm diameter, and was used after dilution 1 in 10 with PBS-T. The labelling reagent (Janssen Pharmaceutical Ltd, Wantage OX12 0DQ) was then drained from the grid and this was washed by floating for $1 \mathrm{~min}$ on each of five successive drops of distilled water.

The labelled specimen was negatively stained by applying to the grid one drop of distilled water and one drop of methylamine tungstate $1 \%$ (Emscope Laborato- 
ries Ltd, Ashford TN23 2LN). Excess liquid was removed with filter paper, and the specimen was allowed to dry. Areas with an even spread of stain were chosen in subsequent examination at $100 \mathrm{kV}$ with a Hitachi H600 transmission electronmicroscope.

\section{Results}

\section{Labelling of surface antigens with protein- $A$ gold (PA-Au)}

Based on colleagues' experience of gold-labelling fimbriae of other organisms, PA-Au was chosen to label the surface antigens of $B$. pertussis; initially this approach was successful. Fig. 1 shows organisms of the three serotypes treated with agglutinin 1 and labelled with PA-Au. A concentration of gold particles can be seen on the cell surface of each of the serotypes $(1,2,3 ; 1,2$ and 1,3)-on which agglutinogen 1 is a common antigen. Gold particles also appear on long projections from the cells of the fimbriate types $(1,2,3$ and 1,2 ; figs. $1 \mathrm{a}$ and $\mathrm{b})$ : these are probably bundles of agglutinated fimbriae. It appears, therefore, that agglutinogen 1 is present both on fimbriae and the cell-surface.

Fig. 2 shows the three serotypes after treatment with agglutinin 2 and PA-Au. As expected, there was no labelling by gold particles of type 1,3 organisms (fig. 2c). In contrast, the fimbriate cells of type 1,2,3 (fig. 2a) and type 1,2 (fig. 2b) show many gold particles along the bundles of agglutin- ated fimbriae, confirming the evidence of many workers that agglutinogen 2 is a fimbrial antigen.

Repeated attempts to label organisms with agglutinin 3 and PA-Au were unsuccessful, even after many variations in the concentration of reagents. To determine if this antigen had been affected by lyophilisation (although the type 1,2,3 and type 1,3 strains still agglutinated readily with agglutinin 3), a freshly isolated type 1,3 strain was examined; but there was no localisation of gold particles in excess of the background distribution (fig. 3a).

\section{Labelling of surface antigens with immunoglobulin- $G$ gold (IgG-Au)}

Because labelling with agglutinin 3 and PA-Au failed, IgG-Au was tested as an alternative; clusters of gold particles were seen on the cell surface of the freshly isolated type 1,3 strain (fig. 3b), but fimbriae were not seen.

IgG-Au and agglutinin 3 also labelled a selection of lyophilised strains. As expected, there was no labelling of the type 1,2 strain (fig. 4b), but clear labelling of the type 1,2,3 and type 1,3 organisms (fig. $4 \mathrm{a}$ and $\mathrm{c}$ ). However, as with the fresh isolate, the gold particles adhered to the cell surface; and there was little attachment to fimbriae even on the fimbriate type 1,2,3 organisms (fig. 4a).

As evidence of the specificity of labelling, when organisms of each serotype were treated with PBS
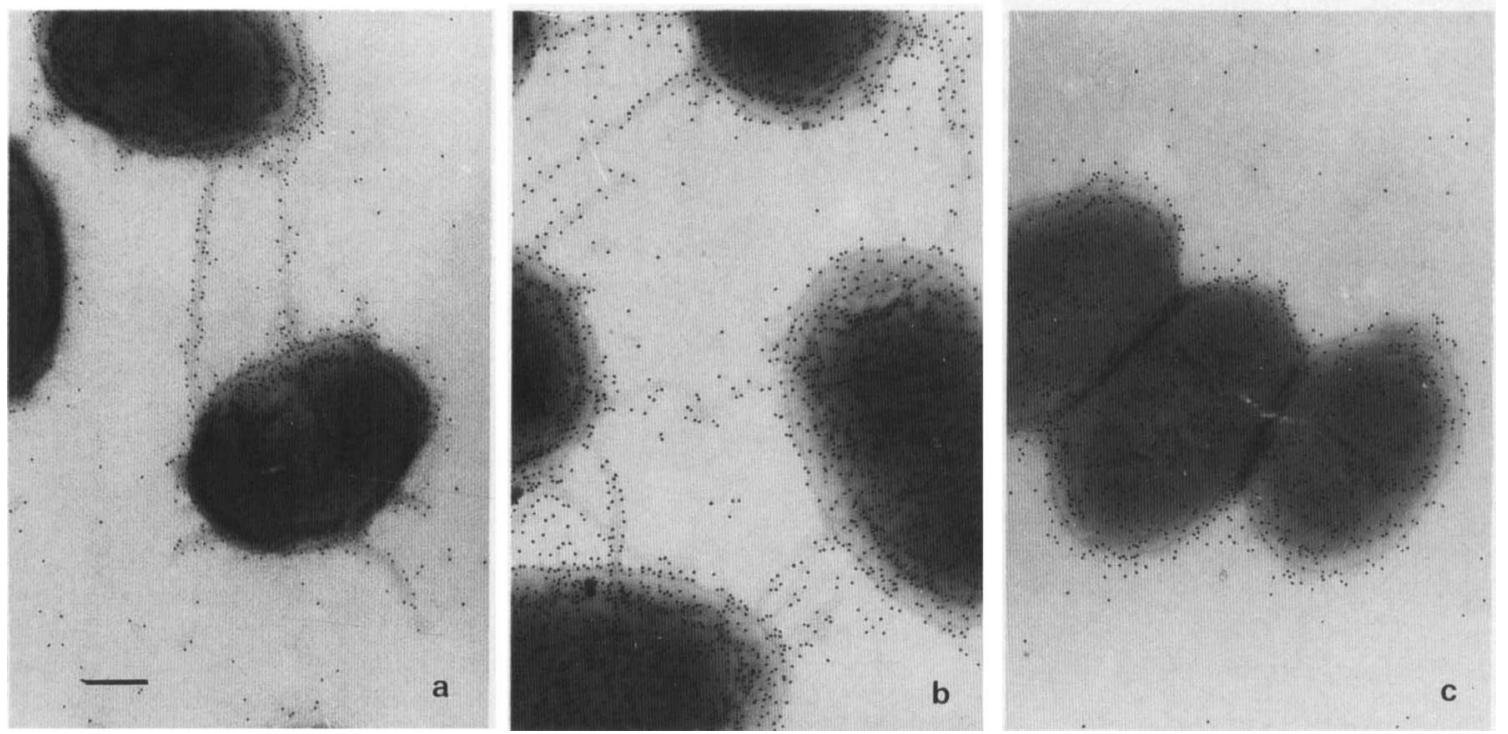

Fig. 1. Electronmicrographs of three strains of B. pertussis treated with agglutinin 1 and protein-A gold: (a) strain 18335 (type 1,2,3) and (b) strain 8002 (type 1,2) showing gold-labelling of fimbriae and of the cell surface; (c) strain A36752 (type 1,3) labelled only on the cell surface. $\mathrm{Bar}=0 \cdot 25 \mu \mathrm{m}$. 



Fig. 2. Electronmicrographs of three strains of B. pertussis treated with agglutinin 2 and protein-A gold: (a) strain K19587 (type $1,2,3$ ) and (b) strain 85068 (type 1,2) labelled only on fimbriae; (c) strain 220822 (type 1,3) showing no gold-labelling. Bar $=0 \cdot 25 \mu \mathrm{m}$.
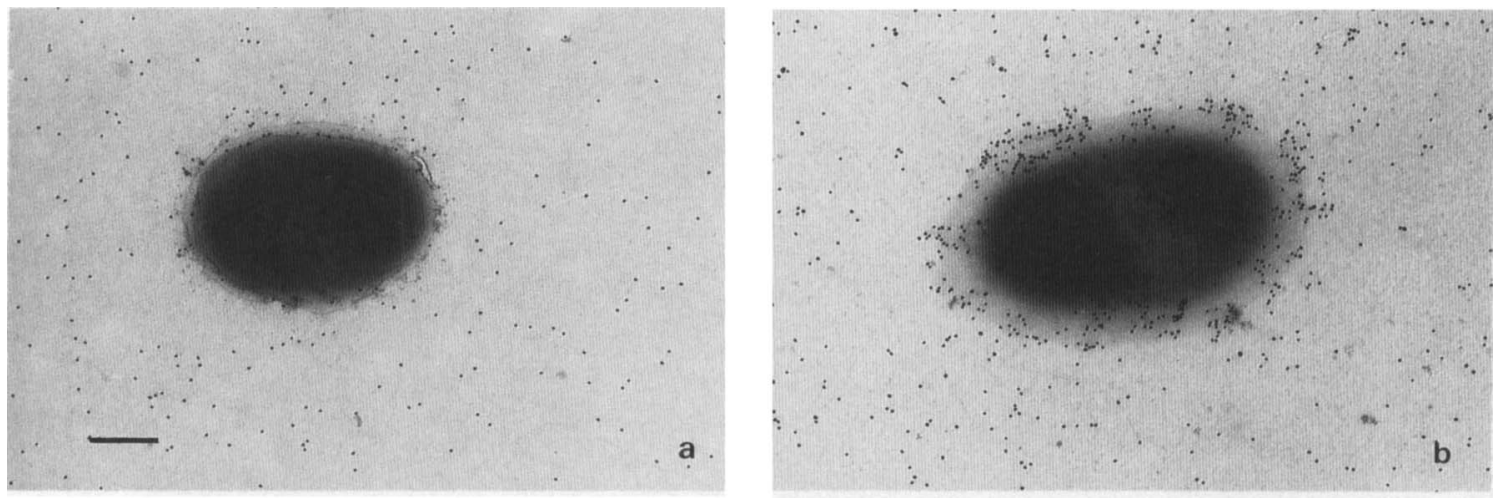

Fig. 3. Electronmicrographs of a fresh isolate of $B$. pertussis type 1,3 treated with agglutinin 3 and also with (a) protein-A gold, showing no gold-labelling, or (b) IgG gold, showing labelling of the cell surface. Bar $=0 \cdot 25 \mu \mathrm{m}$.

instead of typing sera, before gold labelling, only a few gold particles appeared scattered in the background, and there was virtually no non-specific attachment to bacteria (fig. 5). However, it is noteworthy that, as in a previous study, ${ }^{2}$ negatively stained fimbriae were seen on the cells of type $1,2,3$ and 1,2 strains (fig. 5a and b) but not on type 1,3 cells (fig. 5c).

These results are summarised in the table.

\section{Discussion}

Accumulated evidence ${ }^{7}$ shows that children are inadequately protected against whooping cough if pertussis vaccine lacks one or more of the three major agglutinogens; for many years, WHO has recommended that the three agglutinogens be present in whole-cell vaccines.

Recently, the possible use of acellular vaccines has focussed much attention on two componentspertussis toxin and filamentous haemagglutinin. Although an immune response to these has a rôle in protecting mice against experimental infection with an atypical laboratory strain, ${ }^{7}$ evidence of their importance in provoking protection in children is lacking. In Sweden, ${ }^{8}$ vaccine containing both components protected poorly in spite of a good serological response; indeed, protection was not 

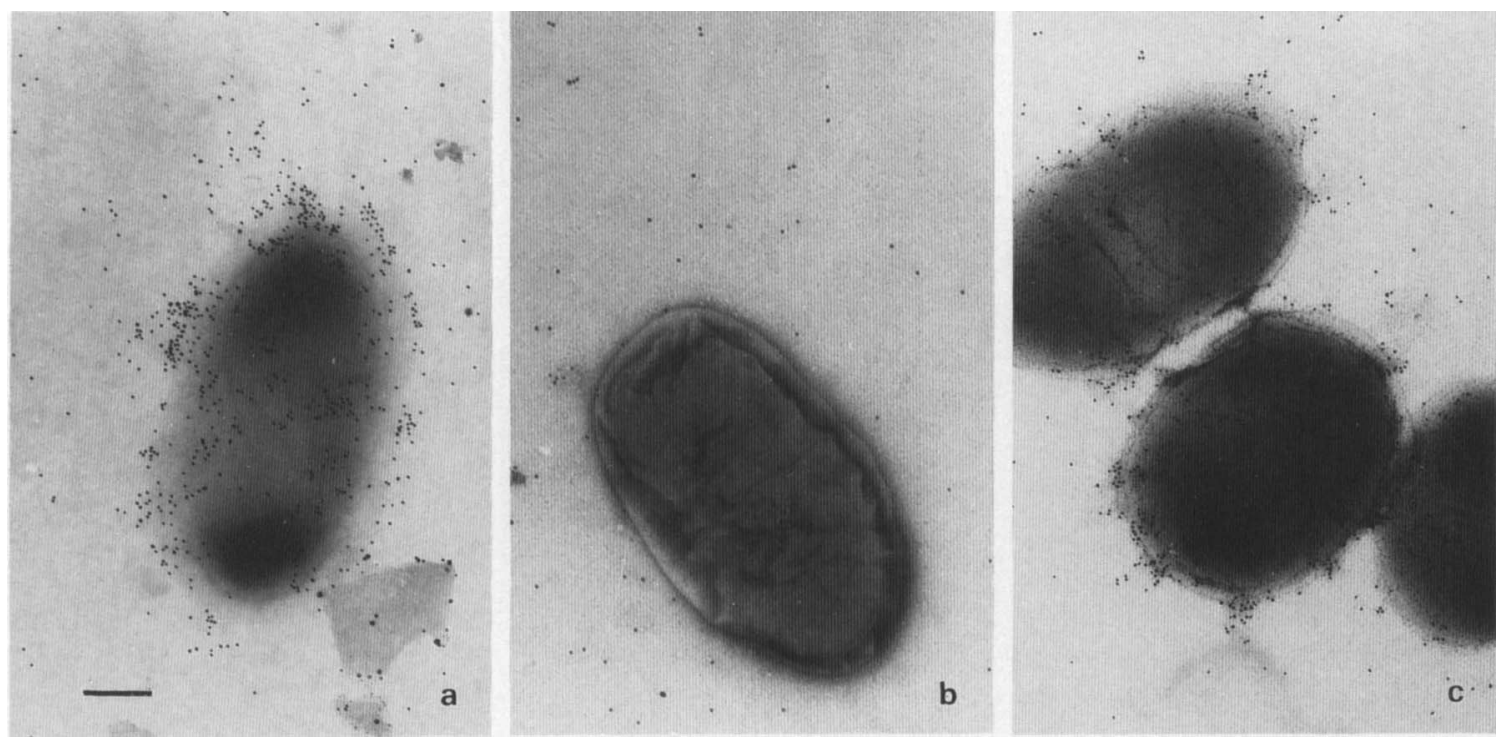

Fig. 4. Electronmicrographs of three strains of $B$. pertussis treated with agglutinin 3 and IgG gold: (a) strain K19587 (type 1,2,3) and (c) strain 220822 (type 1,3) showing labelling of the cell surface; (b) strain 8002 (type 1,2) showing no gold-labelling. Bar $=0 \cdot 25 \mu \mathrm{m}$.
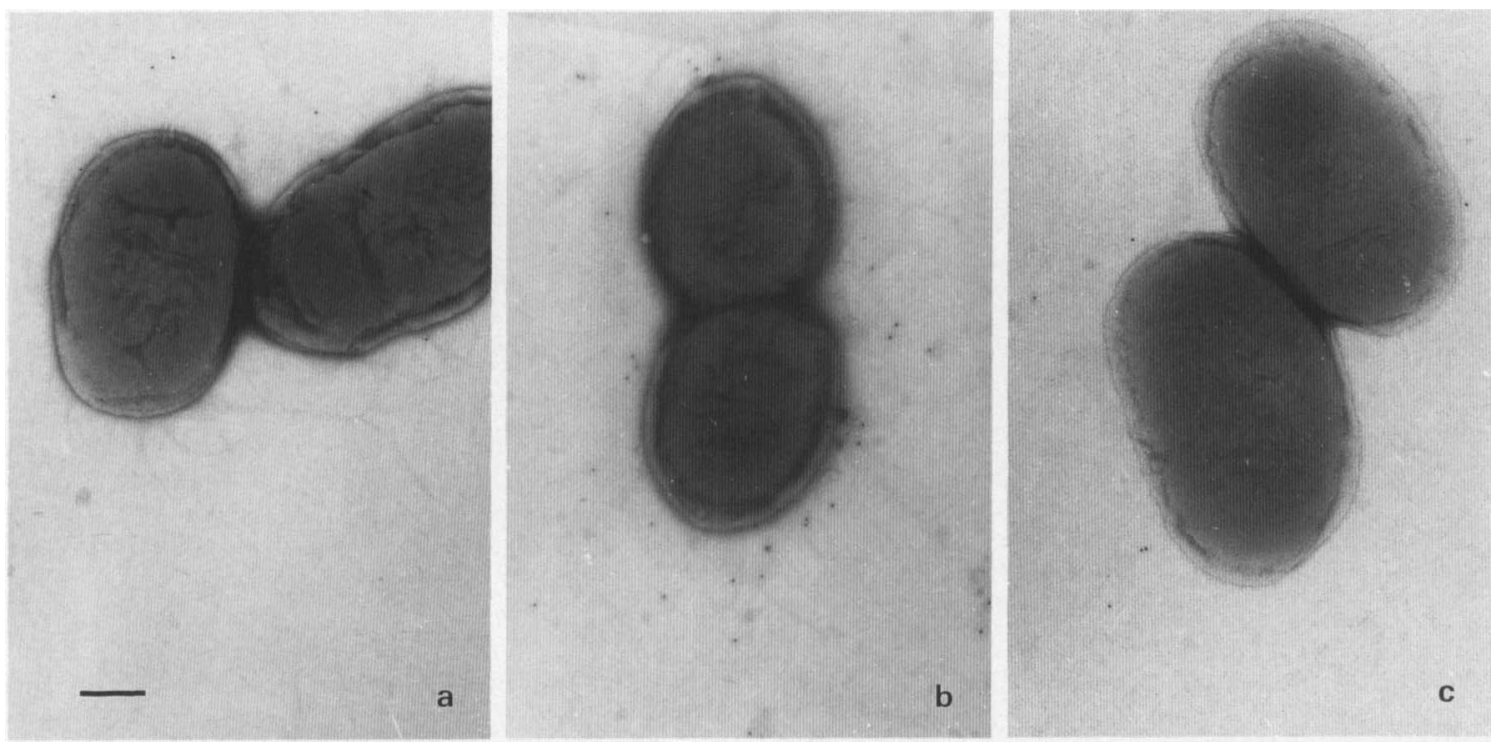

Fig. 5. Control electronmicrographs of three preparations in which PBS replaced agglutinin in the immuno-gold labelling technique: (a) strain 18335 (type 1,2,3) and (b) strain 85068 (type 1,2) showing negatively stained fimbriae; (c) strain A36752 (type 1,3) which does not show fimbriae. All three strains have only a few scattered gold particles in the background, with no evidence of non-specific labelling. $\mathrm{Bar}=0.25 \mu \mathrm{m}$.

related to the levels of antibodies to these two components. Unfortunately, the response to the three agglutinogens was not investigated. ${ }^{9}$

There are conflicting reports on the nature of the agglutinogens and their association with surface structures. It is not clear where agglutinogen 1 is located; the finding in the present study of this antigen on both fimbriae and the cell surface suggests that it may not be a single entity. However, a wealth of evidence on type-specific immunity in 
Table. Location of agglutinogens on the three main serotypes of $B$.pertussis

\begin{tabular}{|c|c|c|c|c|c|c|}
\hline \multirow[b]{2}{*}{$\begin{array}{l}\text { Strain } \\
\text { no. }\end{array}$} & \multirow[b]{2}{*}{ Serotype } & \multirow[b]{2}{*}{ Fimbriation } & \multicolumn{4}{|c|}{ Site of immuno-gold labelling of bacteria treated with } \\
\hline & & & agglutinin 1 & agglutinin 2 & agglutinin 3 & $\begin{array}{c}\text { phosphate- } \\
\text { buffered saline }\end{array}$ \\
\hline $\left.\begin{array}{l}\text { K19587 } \\
18335\end{array}\right\}$ & $1,2,3$ & + & $\mathrm{F}$ and $\mathrm{CS}$ & $\mathrm{F}$ & $\mathrm{CS}$ & none \\
\hline $\begin{array}{l}85068 \\
8002\end{array}$ & 1,2 & + & $\mathrm{F}$ and $\mathrm{CS}$ & $\mathrm{F}$ & none & none \\
\hline $\left.\begin{array}{l}\text { A36752 } \\
220822\end{array}\right\}$ & 1,3 & - & $\mathrm{CS}$ & none & CS & none \\
\hline
\end{tabular}

F, fimbriae; CS, cell surface.

human pertussis suggests that agglutinogens 2 and 3 are of greater importance than agglutinogen 1 which is common to all serotypes of the infecting organism $(1,2,3 ; 1,2$ and 1,3$)$.

There is general agreement that agglutinogen 2 is fimbrial; and a rôle for fimbriae in mucosal attachment is consistent with the predominance of strains possessing agglutinogen 2 (types 1,2,3 and $1,2)$ in non-vaccinated communities, ${ }^{10}$ uninfluenced by the effects of vaccines deficient in one or more of the major agglutinogens.

The site of agglutinogen 3 is less certain. The present study confirms an earlier finding ${ }^{2}$ that it is not fimbrial; this is consistent with the evidence ${ }^{7,10}$ that it promotes colonisation less efficiently, and comes to predominate only in communities that have been immunised against strains containing agglutinogen 2 . Nevertheless, there are reports that agglutinogen 3 is also fimbrial, ${ }^{1,11}$ though these fimbriae have been described as less numerous and present on a smaller proportion of cells ${ }^{1}$ than with agglutinogen 2 . One report ${ }^{11}$ designates this third major antigen "agglutinogen 6"; but it is probable ${ }^{6}$ that this is the entity which most workers with this organism designate "agglutinogen 3".

There are several possible explanations of these discrepancies. First, in the present study organisms were grown on solid medium, whereas others have used liquid cultures which may enhance fimbriation; if type 1,3 organisms are poorly fimbriate in the respiratory tract, this could explain

\section{REFERENCES}

1. Ashworth L A E, Irons L I, Dowsett A B. The antigenic relationship between serotype-specific agglutinogen and fimbriae of Bordetella pertussis. Infect Immun 1982; 37: $1278-1281$.

2. Carter E J, Preston N W. Association between Bordetella pertussis agglutinogen 2 and fimbriae. J Med Microbiol $1984 ; 18: 87-94$. their lesser efficiency in colonisation. Second, because of the relatively high frequency in the variation of serotype in strains of $B$. pertussis, ${ }^{12}$ we have always checked our cultures for serological purity immediately before examining them by electronmicroscopy; other reports mention no such precaution, so that the low percentage of fimbriate cells in type 1,3 cultures could be explained by the presence of fimbriate type $1,2,3$ mutants. Third, the apparent reaction of fimbriae with antibody 3 , reported elsewhere, ${ }^{11,13}$ could follow non-specific attachment to factor-1 or factor2 fimbriae, or the presence of unabsorbed antibody 1 in the antibody 3 preparation; or, in the case of monoclonal antibody 3 , the reagent may be detecting a different epitope from that on which the original serotyping with absorbed antisera was based. ${ }^{14}$

On current evidence, agglutinogen 3 can be thought of as a non-fimbrial outer membrane protein. Whether or not there are conditions under which this antigen may be fimbrial, there is sufficient evidence that vaccine should contain both agglutinogens 2 and 3 , and that preparations of fimbriae may not include both components. The incorporation of fimbriae in newer acellular vaccines may be helpful; but, for protection against type 1,3 infection, it would be necessary to ensure that vaccinees achieved an agglutinin- 3 response as well as the predominantly agglutinin- 2 response likely to be produced by fimbriae.

3. Zhang J M, Cowell J L, Steven A C, Carter P H, McGrath P P, Manclark C R. Purification and characterization of fimbriae isolated from Bordetella pertussis. Infect Immun 1985; 48: 422-427.

4. Steven A C, Bisher M E, Trus B L, Thomas D, Zhang J M, Cowell J L. Helical structure of Bordetella pertussis fimbriae. J Bacteriol 1986; 167: 968-974.

5. Preston N W. Technical problems in the laboratory 
diagnosis and prevention of whooping-cough. Lab Pract 1970; 19: 482-486.

6. Preston N W, Surapatana N, Carter E J. A reappraisal of serotype factors 4, 5 and 6 of Bordetella pertussis. J Hyg (Lond) $1982 ; 88: 39-46$.

7. Preston N W. Pertussis today. In: Wardlaw A C, Parton R (eds) Pathogenesis and immunity in pertussis. Chichester, Wiley. 1988: 1-18.

8. Ad hoc group for the study of pertussis vaccines. Placebocontrolled trial of two acellular pertussis vaccines in Sweden - protective efficacy and adverse events. Lancet $1988 ; 1$ : $955-960$.

9. Preston N W. Placebo-controlled trial of two acellular pertussis vaccines in Sweden-protective efficacy and adverse events. Abstr Hyg Comm Dis 1988; 63: 809.

10. Preston N W. Prevalent serotypes of Bordetella pertussis in non-vaccinated communities. $J$ Hyg (Camb) 1976; 77 : 85-91.

11. Cowell J L, Zhang J M, Urisu A et al. Purification and characterization of serotype 6 fimbriae from Bordetella pertussis and comparison of their properties with serotype 2 fimbriae. Infect Immun 1987; 55: 916-922.

12. Stanbridge $\mathbf{T} \mathbf{N}$, Preston N W. Variation of serotype in strains of Bordetella pertussis. J Hyg (Camb) 1974; 73: 305-310.

13. Ashworth L A E, Dowsett A B, Irons L I, Robinson A. The location of surface antigens of Bordetella pertussis by immuno-electron microscopy. Dev Biol Stand 1985; 61 : 143-151 .

14. Andersen E K. Serological studies on $H$. pertussis, $H$. parapertussis and H. bronchisepticus. Acta Pathol Microbiol Scand 1953; 33: 202-224. 